\title{
Correlative and dynamic in situ S/TEM characterization of heavily irradiated pyrochlores and fluorites.
}

\author{
T.G. Holesinger ${ }^{1}$, S. Dey ${ }^{4}$, J.A. Aguiar ${ }^{3}$, P.A. Papin ${ }^{2}$, J.A. Valdez ${ }^{2}$, Y. Wang, B.P. Uberuaga ${ }^{2}$, and \\ R.H.R. Castro ${ }^{4}$ \\ 1. Materials Physics and Applications Div., Los Alamos National Laboratory, Los Alamos, NM, 80465 \\ 2. Materials Science and Technology Div., Los Alamos National Laboratory, Los Alamos, NM, 80465 \\ ${ }^{3 .}$ Microscopy and Imaging Group, National Renewable Energy Laboratory, Golden, CO, 80401 \\ 4. Dept. of Chemical Engineering and Materials Science, \& NEAT ORU, University of Davis, Davis, CA \\ 95616.
}

Irradiation of materials with light and heavy ions is a ubiquitous method for altering materials to examine their structural and functional processes. For example, materials for applications in highradiation environments, such as nuclear reactors or radioactive waste, require extremely high resistance to damage accumulation, amorphization, and/or volume swelling. The level to which these materials can tolerate damage is often probed with ion irradiation. ${ }^{[1]}$ It can also be used to induce anion and cation disorder within the materials. This disorder can be connected to the defect kinetics within the material and their effects on diffusion and conductivity. For example, it has been observed that the oxygen mobility increases in pyrochlores with an increase in the crystalline disorder. ${ }^{[2]}$

In this talk, we will examine heavy-ion irradiated $\left(\mathrm{Kr}^{+}, 400 \mathrm{keV}\right.$, room temperature) $\mathrm{Ga}_{2} \mathrm{Ti}_{2} \mathrm{O}_{7}$ and $\mathrm{Ga}_{2} \mathrm{Zr}_{2} \mathrm{O}_{7}$ pryochlores as well as nanostructured yttria-stablized zirconia (YSZ). ${ }^{[3]}$ In the case of the pyrochlores, the differences in the resulting microstructures between the $\mathrm{Ga}_{2} \mathrm{Ti}_{2} \mathrm{O}_{7}$ (amorphous) and $\mathrm{Ga}_{2} \mathrm{Zr}_{2} \mathrm{O}_{7}$ (fluorite) and the stability of these structures and associated defects were determined before and after subsequent annealing. The nanostructured YSZ (10 at.\%) was characterized for the observed grain growth and crack structures in the irradiated region and the stability of this structure upon further heating. Conventional (S)TEM was used to characterize the materials before and after irradiation to track the structural stability in each material. In situ (S)TEM was used to examine the evolution of microstructures at elevated temperatures within an atmospheric gas cell, hot-stage holder. Of particular interest was the stability of the materials and defects within the $\mathrm{Kr}$ implanted region (Figure 1), and any transient behavior as the materials are raised in temperature. Use of the in situ atmospheric holder allows for the exploration of dynamic, atomistic-scale processes (Figure 2) at temperature and under gas flow. Examination of the specimen surrounded by an oxidizing atmosphere within the (S)TEM alleviates specimen changes that may result from oxygen loss through heating and holding at temperature in vacuum. The combination of these two approaches will help to understand the dynamic processes regarding damage accumulation and defect stability/kinetics in ion irradiated ceramics. ${ }^{[4]}$

\section{References:}

[1] K. E. Sickafus, L. Minervini, R. W. Grimes, J. A. Valdez, M. Ishimaru, F. Li, K. J. McClellan and T. Hartmann, Science 2000, 289, 748-751.

[2] P. J. Wilde and C. R. A. Catlow, Solid State Ionics 1998, 112, 173-183.

[3] S. Dey, J. W. Drazin, Y. Wang, J. A. Valdez, T. G. Holesinger, B. P. Uberuaga and R. H. R. Castro, Sci. Rep. 2015, 5. 
[4] This work was supported by the U.S. Department of Energy, Office of Science, Basic Energy Sciences, Materials Sciences and Engineering Division and the UC Lab Fees Research Program 12-LF239032.

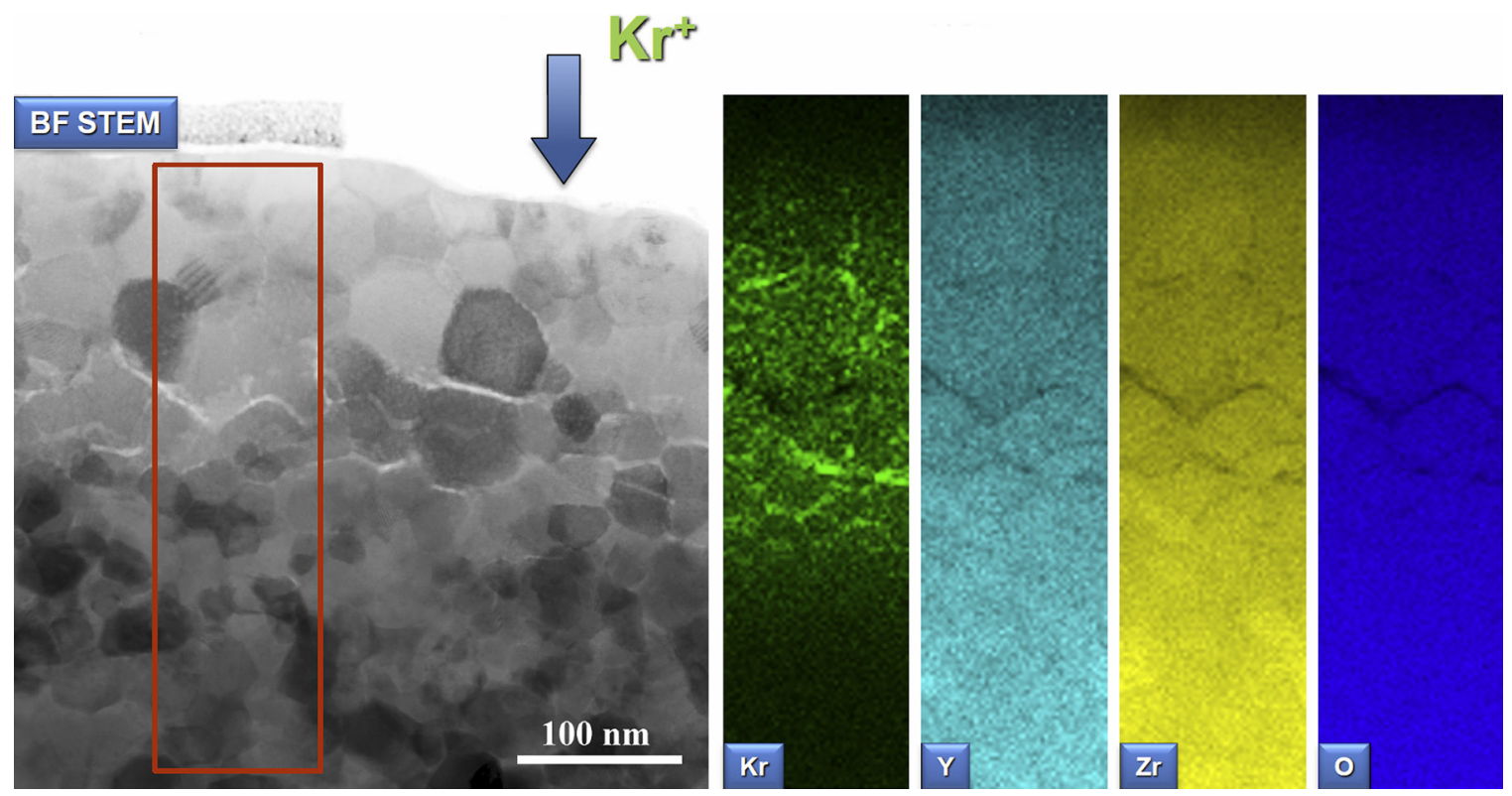

Figure 1. STEM spectral imaging of the $\mathrm{Kr}$ distribution and the local microstructure in nanocrystalline YSZ. Grain growth in the irradiated area has occurred as a result of the irradiation process. The stability and transient behavior of the microstructure and $\mathrm{Kr}$ distribution will be determined from in situ annealing experiments under gas flow in the S/TEM.
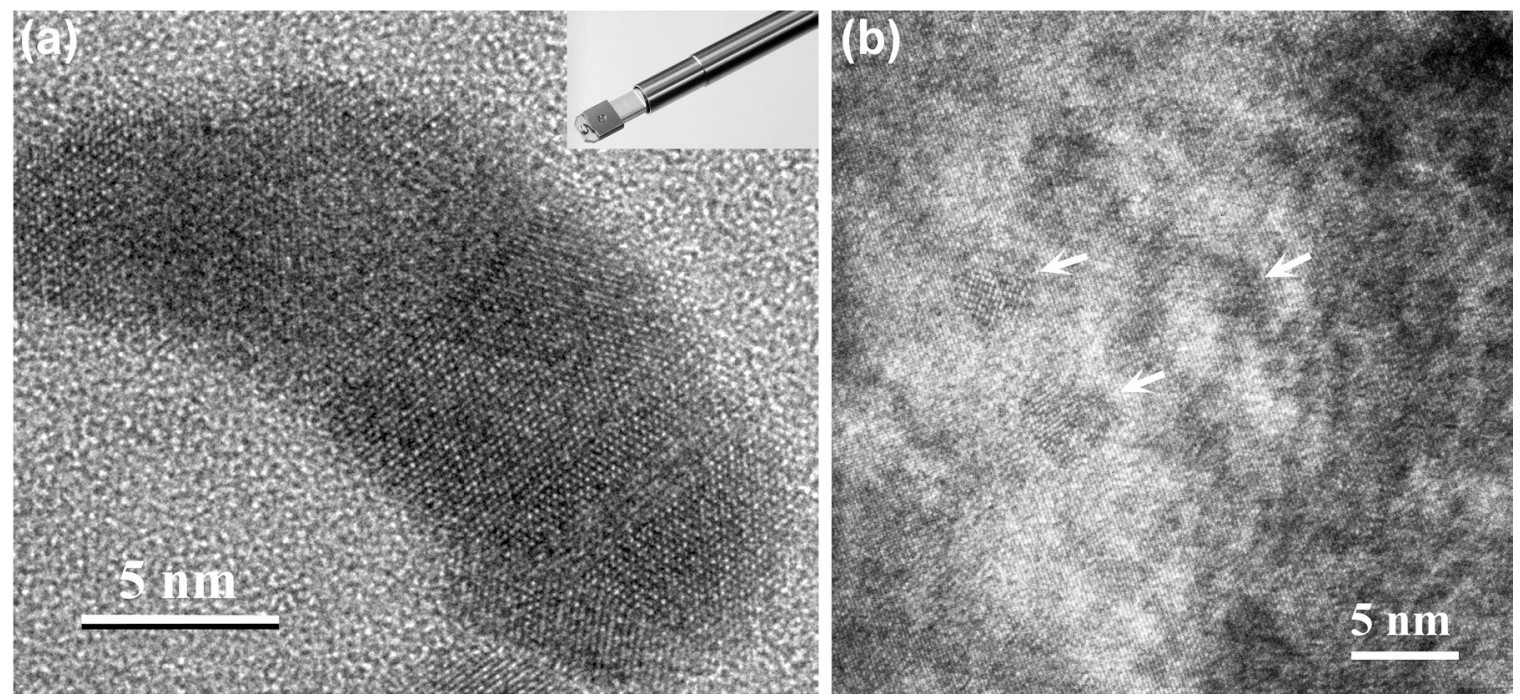

Figure 2. High resolution imaging of in situ alloying of nanoparticles (a) under gas flow at 500C in the in situ gas holder demonstrates the ability to image dynamic processes in the S/TEM at the atomic level. The nm-sized defects induced during $\mathrm{Kr}$ irradiation (b) will be monitored as a function of time and temperature to track defect movement, interactions, and coalescence. 